\title{
Design and experiment of the environment control system for the industrialized production of Agaricus bisporus
}

\author{
Kaixuan Zhao ${ }^{1,2}$, Xuefeng Zhu ${ }^{1}$, Hao Ma ${ }^{1}$, Jiangtao $\mathrm{Ji}^{1,2^{*}}$, Xin $\mathrm{Jin}^{1}$, Jingwei Sun ${ }^{1}$ \\ (1. College of Agricultural Equipment Engineering, Henan University of Science and Technology, Luoyang 471000, Henan, China; \\ 2. Henan Joint International Research Laboratory of Intelligent Agricultural Equipment Technology, Luoyang 471003, Henan, China)
}

\begin{abstract}
Environment parameters are the main factors affecting the growth and development of Agaricus bisporus. Because of the requirements of environmental conditions for high-efficiency industrialized production of Agaricus bisporus, equipments for environment control were developed. Based on the variable operating equipment, a multi-factor fuzzy controller was designed to realize the comprehensive control of ambient temperature, humidity, $\mathrm{CO}_{2}$ concentration, and the temperature and moisture of the compost. The test results showed that the temperature control error was less than $\pm 0.5^{\circ} \mathrm{C}$ and the response speed was more than $0.5^{\circ} \mathrm{C} / \mathrm{h}$; The control error of ambient humidity was less than $\pm 2 \% \mathrm{RH}$, and the response speed was more than $9 \% \mathrm{RH}$ per hour; The moistures at different points in compost ranged from $50 \%$ to $70 \%$ with a standard deviation of 4.04 . The control accuracy of environmental $\mathrm{CO}_{2}$ concentration was within $200 \mu \mathrm{mol} / \mathrm{mol}$. The overall performance of the control system was stable and reliable, which could meet the requirements of environment factors for the growth of Agaricus bisporus. The system can provide technical support and reference for the automatic and precise control of the environment during the industrialized production of Agaricus bisporus.
\end{abstract}

Keywords: environment control system, Agaricus bisporus, industrialized production, vertical agriculture, fuzzy controller, design, experiment

DOI: $10.25165 /$ j.ijabe.20211401.5635

Citation: Zhao K X, Zhu X F, Ma H, Ji J T, Jin X, Sun J W. Design and experiment of the environment control system for the industrialized production of Agaricus bisporus. Int J Agric \& Biol Eng, 2021; 14(1): 97-107.

\section{Introduction}

Agaricus bisporus is an edible basidiomycete mushroom. It is rich in amino acids, vitamins, minerals and other substances, has the effects to improve human immunity ${ }^{[1]}$. It is one of the most widely cultivated mushrooms with the highest yield and the largest consumption of edible fungi in the world ${ }^{[2,3]}$. At present, more than 70 countries are engaged in commercial production of the Agaricus bisporus $^{[4]}$, which accounts for $70 \%$ of the total edible fungus production $^{[5]}$. In recent years, with the gradual improvement of people's living standards and scientific diet awareness, the market development potential of Agaricus bisporus has been continuously improved. The large-scale and industrialized production of Agaricus bisporus has become the inevitable trend and means for the rapid development of Agaricus bisporus industry in the future ${ }^{[6,7]}$. The efficient growth of Agaricus bisporus requires suitable

\section{Received date: 2020-01-03 Accepted date: 2020-07-06}

Biographies: Kaixuan Zhao, PhD, Lecturer, research interest: intelligent equipment for the industrialized production of Agaricus bisporus, Email: kx.zhao@haust.edu.cn; Xuefeng Zhu, Master candidate, research interest: Environmental control system for the industrialized production of Agaricus bisporus, Email: zhuxuefeng1994@163.com; Hao Ma, PhD, Lecturer, research interest: intelligent grading system of Agaricus bisporus, Email: mah85@ cau.edu.cn; Xin Jin, PhD, Associate Professor, research interest: precision operation and detection system for intelligent agricultural equipment, Email: jx.771@163.com; Jingwei Sun, Master candidate, research interest: intelligent detection of external quality of Agaricus bisporus, Email: sunjingwei969@ 163.com.

*Corresponding author: Jiangtao Ji, $\mathrm{PhD}$, Professor, Dean, research interest: intelligent agriculture equipment for industrialized production of edible fungus. College of Equipment Agricultural Engineering, Henan University of Science and Technology, Luoyang, 471003, Henan, China. Tel: +86-379-64877837, Email: jjt0907@163.com. environmental conditions. Therefore, it is essential to regulate the environmental factors within the most suitable range, to guarantee high yield and high quality of Agaricus bisporus in large-scale industrial production ${ }^{[8]}$.

Many experts and scholars have carried many studies in greenhouse environment regulation. At present, greenhouse environment regulation technologies are sophisticated and mature ${ }^{[9,10]}$, where hardware has developed from single machine control $^{[11]}$ to the Internet of things control ${ }^{[12]}$; control factors have developed from single temperature regulation ${ }^{[13]}$ to multiple factors coordinated regulation such as temperature, light, water and ventilation $^{[14]}$, and environmental regulation methods have gone through single environmental factor control ${ }^{[15,16]}$, integrated environmental control ${ }^{[17]}$, model-based decision-making control ${ }^{[18]}$, economic optimal control ${ }^{[19]}$, crop information feedback optimal control $^{[20,21]}$ and other development stages, the control methods are more and more diversified ${ }^{[22]}$.

In the field of environmental control of edible fungi, in 1947 Bels et al. ${ }^{[23]}$ in the Netherlands first adopted the cultivation of Agaricus bisporus under the environmental control conditions, which opened the precedent of environmental control of edible fungi. Then, countries and regions in Europe, the United States, Brazil and other countries and regions also started the studies of the industrialized production process of edible fungi based on environmental control. Methods for real-time automatic supervision and control of the internal environment of the farmhouse were developed to create suitable environmental conditions for the growth of Agaricus bisporus, and annual stable production was achieved. The studies of the industrialized production of edible fungi started relevantly late. The research on the automatic technologies for edible fungi cultivation has entered a new stage, and some substantive results have been achieved. Han et al. ${ }^{[24]}$ 
developed remote monitoring system using PC machine to communicate with the controller via an Ethernet network. Through the secondary development of configuration software, the environmental parameters can be collected and monitored remotely in real-time. Kwon et al. ${ }^{[25]}$ designed an environmental control system consisting of a heat pump, a thermal storage tank and a radiator in a variable opening chamber. The developed control system can be used to cultivate high-quality shiitake mushrooms more effectively than a conventional cooler and heater. Song et al. ${ }^{[26]}$ integrated the ZigBee wireless communication technology, Socket communication technology, WebService technology and Android programming to realize the remote control of the environment of edible fungus factory by mobile phone client. However, the studies and development of the automatic cultivation of edible fungi, especially the environmental control system, is still relatively backward. Equipment optimization and function improvement are still needed.

Overall, the research on edible fungi environmental control system is lagging behind, and most of them are for general edible fungi. The environmental requirements of different kinds of edible fungi are varied, and the emphasis on environmental regulation and control for specific species is also different. Compared with other edible fungi, Agaricus bisporus is more sensitive to environment parameters. When the environment is out of optimum, the Agaricus bisporus cap turns opened and brown easily, which severely affects its commercial value. Therefore, the control of the environment for Agaricus bisporus requires higher accuracy. The existing environmental control system cannot meet the need for higher production of the Agaricus bisporus. The current environmental control system only considers the ambient parameters. The studies of integrated regulation and control of ambient and compost and the corresponding technologies are deficient. Therefore, the development of the environment control system suitable for the growth of Agaricus bisporus is imperative.

In this study, an environment control system for industrial production of Agaricus bisporus was designed and developed by using multivariable fuzzy control technology. By combining with Agaricus bisporus' growth agronomy requirements, the real-time control of the environment factors was realized for the industrialized production of Agaricus bisporus, including ambient temperature, ambient humidity, ambient $\mathrm{CO}_{2}$ concentration, and the temperature and moisture of the compost.

\section{Overall design}

\subsection{Objectives of control system}

In the industrialized production of Agaricus bisporus, the main environmental factors are ambient temperature, ambient humidity, $\mathrm{CO}_{2}$ concentration, compost temperature and compost moisture. The growth process of Agaricus bisporus can be divided into two stages: mycelium development and body growth. Different growth stages require different environmental parameters which directly affect the growth speed of mycelium and the differentiation quality and quantity of mushroom body ${ }^{[27,28]}$. During the mycelium development period, the ambient temperature in the mushroom house should be maintained at $20^{\circ} \mathrm{C}-27^{\circ} \mathrm{C}$; the temperature of the compost should be $22^{\circ} \mathrm{C}-25^{\circ} \mathrm{C}$; the ambient relative humidity should be controlled at $70 \%-75 \% \mathrm{RH}$; the optimum moisture of the compost should be in the range of $50 \%-70 \%$; the concentration of $\mathrm{CO}_{2}$ should be controlled at $3000-5000 \mu \mathrm{mol} / \mathrm{mol}$; ventilation in the mushroom house is required. During the growth of the mushroom body, the environment temperature in the mushroom house should be maintained at $15^{\circ} \mathrm{C}-22^{\circ} \mathrm{C}$; the temperature of compost should be $13{ }^{\circ} \mathrm{C}-18^{\circ} \mathrm{C}$; the ambient relative humidity should be controlled at $85 \%-90 \% \mathrm{RH}$; the optimum moisture of the compost should be $50 \%-70 \%$, the concentration of $\mathrm{CO}_{2}$ should be controlled lower than $1000 \mu \mathrm{mol} / \mathrm{mol}^{[29,30]}$. The above-mentioned control range of environmental factors is required for each growth stage. The designed environmental control system should be combined with the growth and agronomy of Agaricus bisporus to control all environmental parameters in a timely and appropriate manner. The control accuracy of compost temperature should be $\pm 1{ }^{\circ} \mathrm{C}$; the control accuracy of ambient relative humidity should be $\pm 2 \% \mathrm{RH}$; the control accuracy of compost moisture should be $\pm 10 \%$; the control accuracy of $\mathrm{CO}_{2}$ concentration should be $\pm 200 \mu \mathrm{mol} / \mathrm{mol}$.

The growth and development of Agaricus bisporus require very little light. The mushroom mycelium and body can grow in dark. Under strong light or direct light, the surface of the mushroom will harden and turn yellow; the handle of the mushroom becomes bent; the cover of the mushroom becomes askew; the quality of the Agaricus bisporus decline ${ }^{[29]}$. The experimental mushroom room only needs to provide weak light for illumination. Therefore, the control system in this design does not control the light conditions.

\subsection{Structure of control system}

According to the functional requirements of the environmental control system for the industrialized production of Agaricus bisporus, the overall architecture of the environmental control system is shown in Figure 1. The control system consists of four parts: interaction interface unit, information acquisition unit, central controller unit and executive control unit. The interaction interface is a touch screen based human-computer interface, which is connected to the central controller unit and used to display the real-time information acquisition from the sensors, and set working parameters of the entire system. The information acquisition unit includes various environmental factor sensors, through which the environment information can be collected. The central controller unit is the core of the whole system, which can receive information from sensors, run fuzzy controller algorithms and send instructions to executive control units. The executive control unit includes a variety of execution equipment, which changes the environment of the mushroom house and makes the Agaricus bisporus grow in a suitable environment.

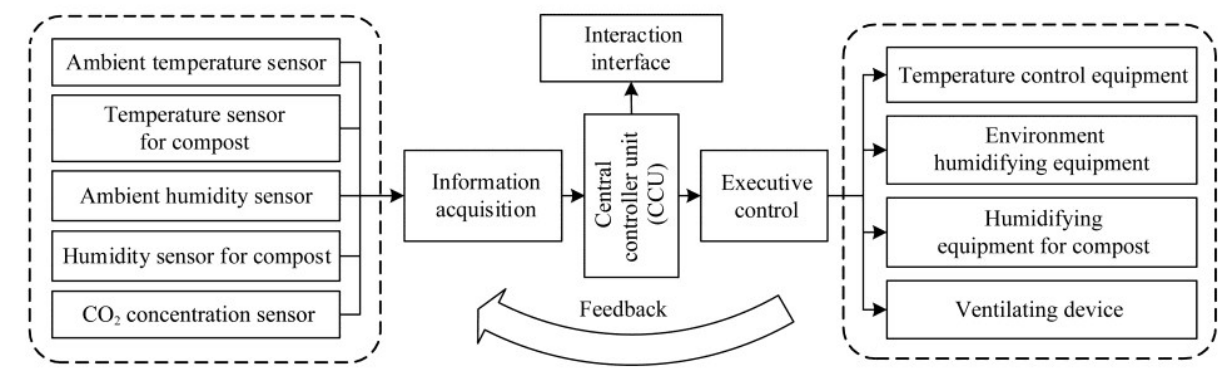

Figure 1 Overall structure of the system 
The sensors collect the environmental information and send it to the central controller, where the collected information is analyzed and processed in combination with the setting of a control strategy to output the instructions to execution units. After receiving the instructions, the executive equipment works to regulate and control the environmental parameters. The sensors and executive units work circularly to keep the environment of the mushroom farm suitable for Agaricus bisporus.

\section{Hardware design}

\subsection{Temperature control system}

The temperature control of the mushroom farm includes two aspects: ambient temperature control and compost temperature control. As shown in Figure 2, the hardware of the temperature control system mainly includes an ambient temperature sensor, compost temperature sensor, temperature regulating equipment and the central controller.

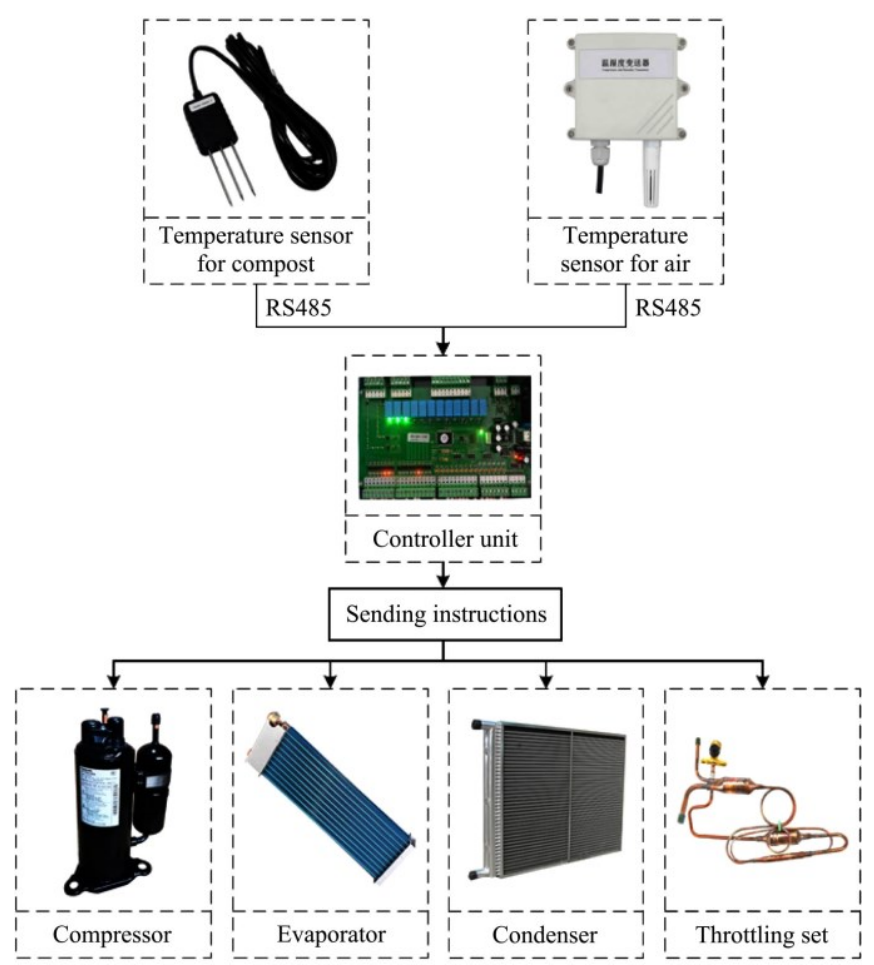

Figure 2 Schematic diagram of temperature control system

The mushroom house environment is humid, and the temperature sensor needs to be waterproof. The system adopted RS-WS-N01-2 temperature and humidity transmitter (Renshuo Electronic Technology Co., Ltd., Jinan, China). The protection grade of the sensor is IP65, with good rain and snow resistance and air permeability. The RS485 bus based modbus-rtu protocol was used to communicate with the central controller. The temperature sensors were arranged on the shelves in the mushroom house. The compost for mushroom growth is a special solid electrolyte with capillary porosity. RS-WS-N01-TR temperature and moisture transmitter (Renshuo Electronic Technology Co., Ltd., Jinan, China) was used to measure the temperature of compost. It is waterproof with good corrosion resistance. The probe is a stainless-steel needle with strong electrolytic resistance and high quality, with a maximum power of $0.4 \mathrm{~W}$. It is necessary to dig a pit vertically with a diameter of about $20 \mathrm{~cm}$ and depth of about $12 \mathrm{~cm}$ on the compost. The sensor is buried and compacted with compost to ensure that the steel needle is in close contact with the compost. The industrial water-cooled air conditioner was used as the temperature regulating executive equipment. Its energy consumption is low and easy for operation and maintenance, with good refrigeration and heating effect and high practicability.

The central controller takes ambient and compost temperature values from sensors as input. After analysis and processing, the central controller sends instructions to the air conditioner to change the refrigerating/heating output. Finally, the environment temperature and compost temperature are regulated to reach the preset value. The change of compost temperature mainly depended on the heat transfer from the air in the mushroom house. Therefore, one temperature regulating execution equipment can realize the control of ambient temperature and compost temperature at the same time.

\subsection{Humidity/moisture control system}

The growth of Agaricus bisporus requires humid environment and the moisture content of compost should keep at 50\%-70\%. Two separate systems were developed to realize the control of ambient humidity and moisture of compost.

The humidity/moisture control system is shown in Figure 3. The working processes of the two systems are similar, where the humidity/moisture value is collected by sensors and sent to the central controller. The central controller controls the execution equipment to spay fog/water to make the humidity/moisture to reach the preset value. The difference between the two systems lies in the difference between the information acquisition sensor and the execution equipment.

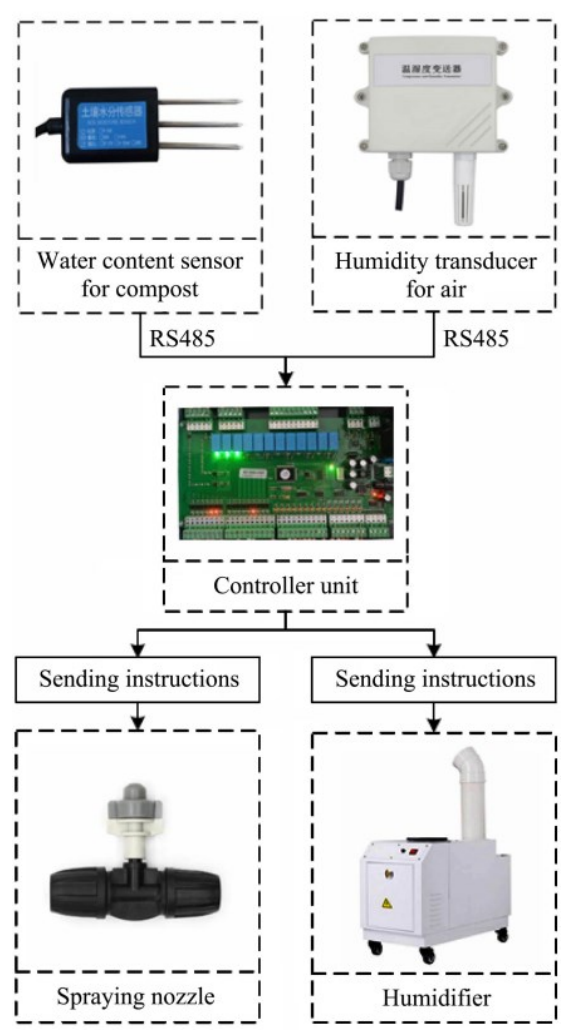

Figure 3 Schematic diagram of humidity/moisture control system

RS-WS-N01-2 temperature and humidity transmitter (Renshuo Electronic Technology Co., Ltd., Jinan, China) was used for the collection of environmental humidity, and Kungchung ly-020y industrial ultrasonic humidifier (Blueprints Environmental Protection Technology Co., Ltd., Shanghai, China) was used to gain humidity in air. This humidifier uses the high-frequency vibration of the atomizing sheet to break the water into small particles and spray them out. The water mist was blown to the mushroom house by the fan along the pipeline. The relative humidity could reach more than $90 \% \mathrm{RH}$ by using this humidifier. The sensor selected 
for the collection of the compost moisture was the same as the temperature control system, i.e., RS-WS-N01-TR temperature and moisture transmitters (Renshuo Electronic Technology Co., Ltd., Jinan, China). The spray execution equipment used the plastro-FLF atomizing nozzle (Prato Irrigation Technology Co., Ltd., Beijing, China). The atomizing nozzle was equipped with a pressure valve to ensure good stop performance. The average spray droplet was $65 \mu \mathrm{m}$, and the atomization performance meets the requirement.

\section{3 $\mathrm{CO}_{2}$ control system}

Compared with temperature and humidity, $\mathrm{CO}_{2}$ concentration is the second most important environmental factor. The main role of $\mathrm{CO}_{2}$ concentration regulation was to inhibit the growth of miscellaneous bacteria and provide a suitable environment for the growth of Agaricus bisporus. Agaricus bisporus is a kind of aerobic bacteria. It needs a lot of oxygen for growth and development and produces $\mathrm{CO}_{2}$. The control of $\mathrm{CO}_{2}$ concentration is mainly realized by the ventilation execution equipment. Similar to the temperature and humidity control, the $\mathrm{CO}_{2}$ concentration in the mushroom house was measured by sensors and transmitted to the central controller. The $\mathrm{CO}_{2}$ concentration control system is shown in Figure 4 .

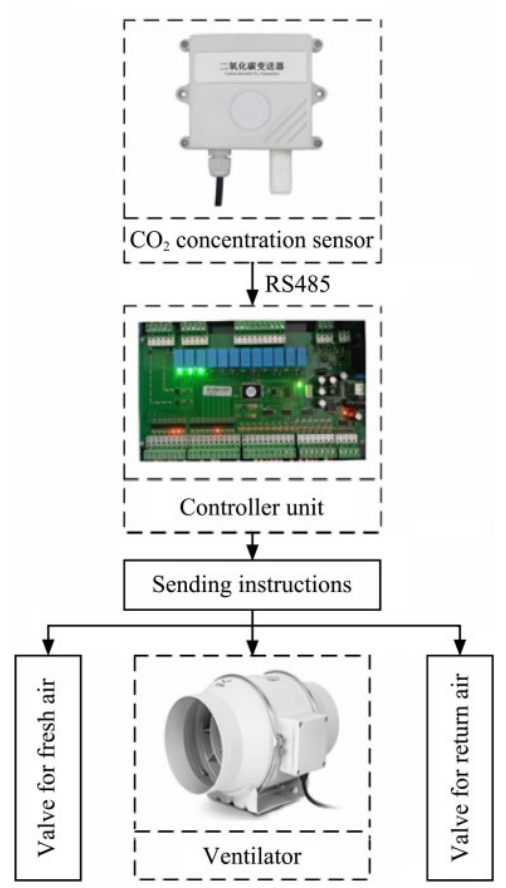

Figure 4 Schematic diagram of $\mathrm{CO}_{2}$ concentration control system

Ventilation execution equipment was controlled to make the $\mathrm{CO}_{2}$ concentration in the mushroom house reach the preset value. RS-CO2-NO1-2 $\mathrm{CO}_{2}$ transmitter (Renshuo Electronic Technology Co., Ltd., Jinan, China) was used in the $\mathrm{CO}_{2}$ control system. The sensor is accurate in measurement, condensation-proof, and has strong anti-interference ability. Ventilation execution equipment consisted of a fresh air valve, return air valve and air blower from air conditioner. By controlling the opening and closing degree of the two valves and the speed of the blower, the $\mathrm{CO}_{2}$ concentration in the mushroom room is adjusted for the growth of Agaricus bisporus. In the control process for reducing $\mathrm{CO}_{2}$ concentration, fresh air from the external environment was sent to the mushroom house through the fresh air valve. In order to ensure the control effect, the fresh air valve is connected to the air circulation environment.

\subsection{Central controller}

As shown in Figure 5, the central controller of the system is mainly used for receiving and processing data, controlling execution equipment and human-machine interaction. The program was written in $\mathrm{C}$ language. In order to control the temperature, humidity and $\mathrm{CO}_{2}$ concentration of the environmental control system, stm32f103zet6 single-chip microcomputer (STMicroelectronics Co Ltd, Geneva, Switzerland) was selected as the controller. The single-chip microcomputer adopts 32-bit embedded processor with arm Cortex-M3 core, RS485 communication technology. Standard Modbus RTU protocol was used for communication. The controller receives and processes the information of various environmental parameters, and controls the execution equipment. The breaker, relay, current transformer and $\mathrm{AC}$ contactor were used together to control the high-power equipment safely. HZ-RF300M frequency converter (Hertz electric equipment sales Co., Ltd., Baoding, China) was used to control the speed of the fan in the air conditioner by changing the frequency of $\mathrm{AC}$ power inputted to the motor.

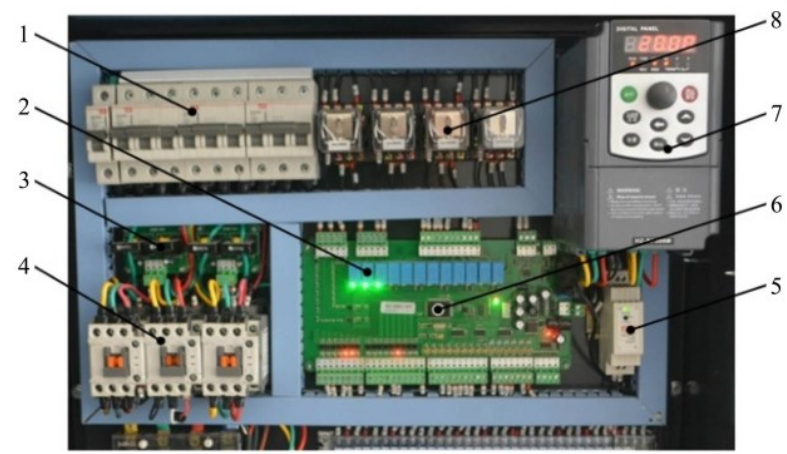

1. Circuit breaker 2. OEG relay 3. Current transformer 4. AC contactor 5. Power switch 6. Single chip microcomputer 7. Frequency converter 8. Electromagnetic relay

Figure 5 Structure of central controller

\section{Software design}

\subsection{Control model}

The environmental control system for industrialized production of Agaricus bisporus is a complex system with non-linear, multi-inputs and multi-outputs. The continuous change of outdoor environment factors constantly affects the condition of environment in mushroom house. The uncertainty is an unavoidable problem in the control system ${ }^{[31-33]}$. Therefore, the control algorithm must adjust its parameters in real-time according to the situation of mushroom house. This system adopted the response principles of the environmental parameters to establish the fuzzy control model for temperature and humidity/moisture regulation. This controller does not need to establish the precise model of the controlled object and has strong robustness. The model is non-linear and time-varying, therefore can be used to solve the problem of environment control of mushroom house ${ }^{[34,35]}$.

\subsubsection{Principle of fuzzy control}

The principle of the fuzzy control model is shown in Figure 6 . When the setting value $r$ is given, the system deviation $e$ is calculated by comparing with the measured values $f$, and the change rate of $e$ is calculated as $e c$. Then fuzzy processing is carried out to obtain fuzzy quantity $E$ and $E C$. According to the experience of human experts, the control rules are established, and the fuzzy reasoning is carried out to obtain the control signal $U$. It is then defuzzified to get the actual control value $u$, which is transformed into an analog signal through a D/A converter to realize the control of the environment parameters. The state of the control object is detected by the sensor, and the analog signal is transformed into a digital signal to form a new state value $f$ through an $\mathrm{A} / \mathrm{D}$ converter, and the feedback control of environmental factors is realized. 


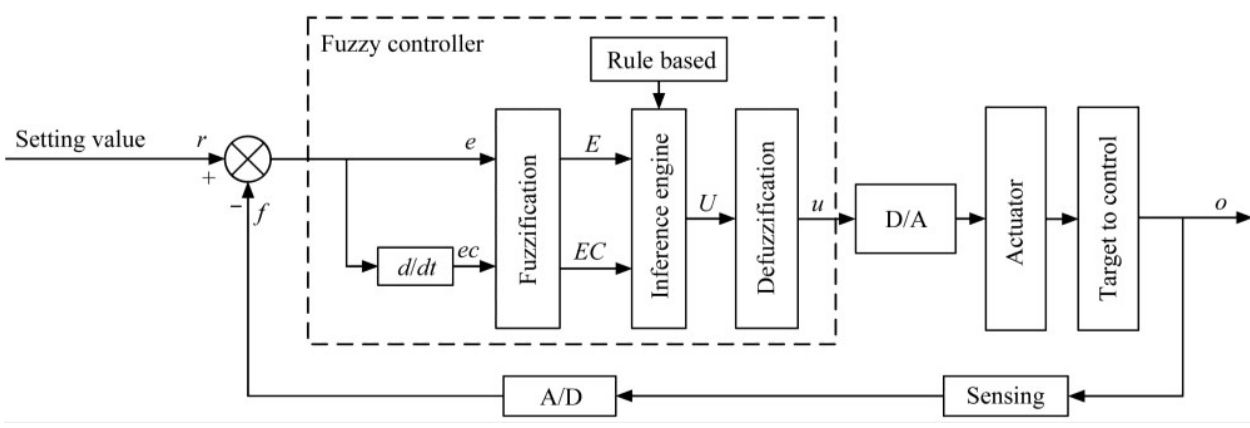

Figure 6 Principle of fuzzy control model

\subsubsection{Fuzzy control system}

The environment control system of industrialized production of Agaricus bisporus is a multi-factor control system. The temperature of compost, environment temperature, moisture of compost, environment humidity and $\mathrm{CO}_{2}$ concentration all affect the growth and development of Agaricus bisporus. The fuzzy control system scheme of this system is shown in Figure 7.

In the process of temperature control, because the mushroom grows on the compost, the compost temperature has a greater impact on the survival and activity of the mushroom. Therefore, the control of compost temperature takes precedence over the control of ambient temperature, and the input value of the control system is selected as the preset compost temperature. The temperature control of the compost in this system is realized by changing the ambient temperature through the air conditioner. The ambient temperature can affect the compost temperature simultaneously. In order to reach the desired temperature in time, there must be a certain difference between the presets of ambient and compost temperature, and the difference must meet certain conditions. If the difference between the two preset temperature values is too small, the response speed of compost temperature control is slow. It takes a long time to reach the preset value and the control efficiency is poor; if the difference between the two preset values is too large, the environment temperature may deviate from the environment temperature range for the growth of Agaricus bisporus. In this case, the growth and development of Agaricus bisporus are affected. As shown in Figure 8a, before the preset compost temperature is inputted into fuzzy controller, it is converted into an equivalent ambient temperature value according to the desire response speed of compost temperature control and the temperature range of Agaricus bisporus. The conversion equation is shown as Equation (1) as follows:

$$
\left\{\begin{array}{c}
T=s t_{s}+R \times e s t \\
e s t=s t_{s}-s t_{c}
\end{array} \quad e t_{s}=\left\{\begin{array}{lc}
\max , & T>\max \\
T, & \min <T<\max \\
\min , & T<\min
\end{array}\right.\right.
$$

where, $s t_{s}$ is the preset temperature value of compost, ${ }^{\circ} \mathrm{C}$; $s t_{c}$ is the actual temperature of compost, ${ }^{\circ} \mathrm{C}$; est is the temperature deviation (preset value minus actual value), ${ }^{\circ} \mathrm{C} ; R$ is the conversion factor, when $R=0, T=s t_{s}$, the response speed of the system is the slowest; $T$ is the temperature value under the condition of considering response speed, ${ }^{\circ} \mathrm{C}$; max is the upper line of temperature for the growth of Agaricus bisporus, ${ }^{\circ} \mathrm{C}$; min is the lower line of temperature for the growth of Agaricus bisporus, ${ }^{\circ} \mathrm{C}$; et $t_{s}$ is the equivalent preset ambient temperature of the system, ${ }^{\circ} \mathrm{C}$.

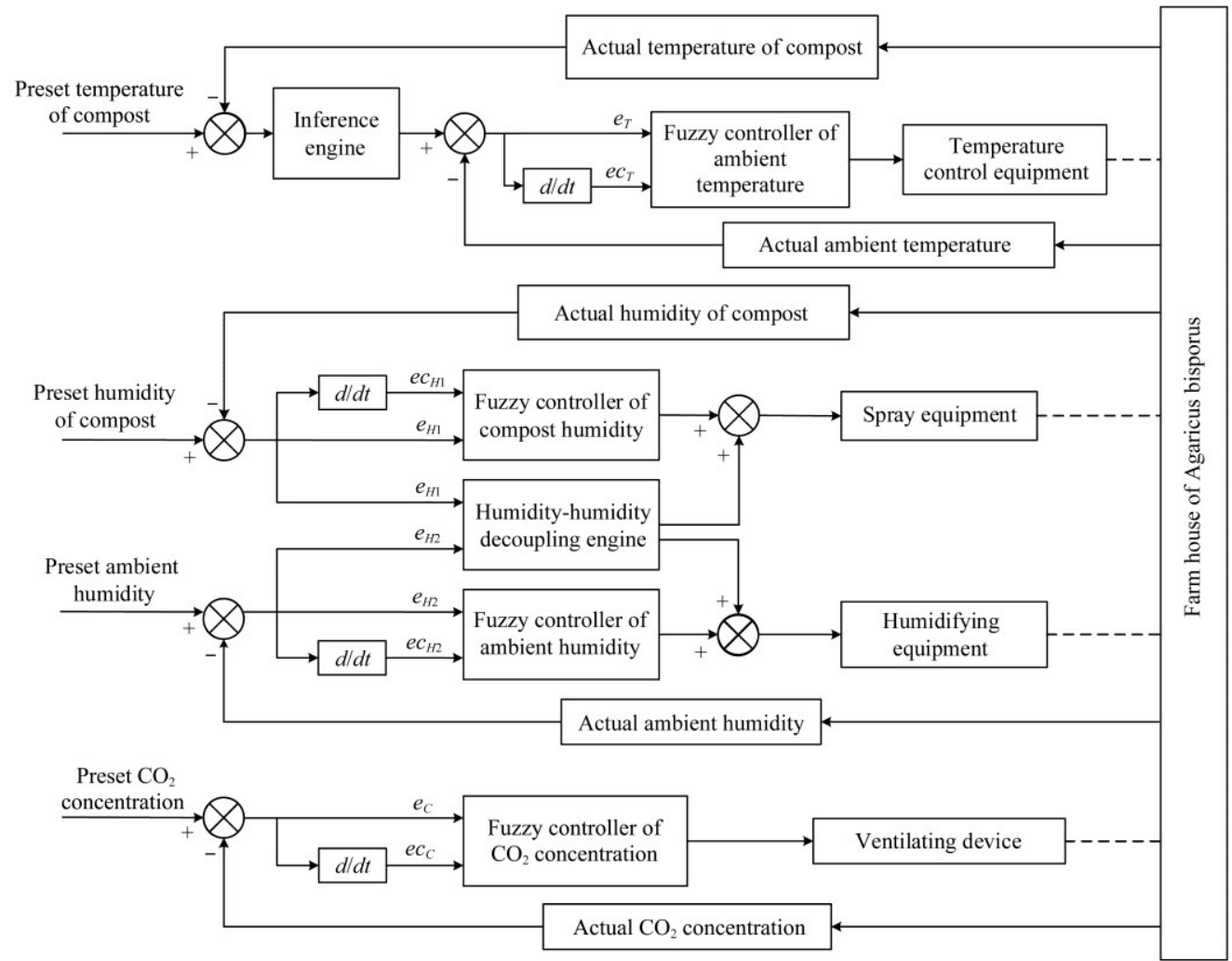

Figure 7 Fuzzy control system for environment factors of Agaricus bisporus 
After the preset value of compost temperature and response speed are determined, preset environment temperature $\left(e t_{s}\right)$ can be calculated by Equation (1). The fuzzy control model took $e_{s}$ as input, and then the temperature of compost was indirectly controlled until the actual temperature reached the expected effect.

In the process of humidity control, there is a cross coupling between the moisture of compost and the environment humidity. The water evaporation of the compost changes with the moisture of compost, which leads to the change of the environmental humidity. Vice versa, when the environment humidity changed, the water molecules in air will also change the permeability of water in the compost. This has an impact on the moisture retention of the compost. If the coupling effect between the temperature and the substrate is neglected, the control precision will be affected. In view of this, the humidity control system adopts the ambient humidity/compost moisture decoupling strategy, which consists of two separate fuzzy control units and a fuzzy decoupling unit. The fuzzy decoupling unit is used to decouple and compensate the two main circuits of compost moisture and environment humidity. The influence of the coupling circuit on the two main circuits is eliminated. Compost moisture and environment humidity were controlled independently. As shown in Figure 8b, the fuzzy decoupler is a dual-input and dual-output fuzzy controller. The input $e_{1}$ is the moisture deviation of the compost, and $e_{2}$ is the environment humidity deviation. According to the prior fuzzy decoupling rules, supplement values for the compost moisture control and environment humidity control are obtained by the fuzzy decoupler. Both supplement values were superimposed with output values of their original fuzzy controllers, and the final control quantities were obtained ${ }^{[33,36]}$.

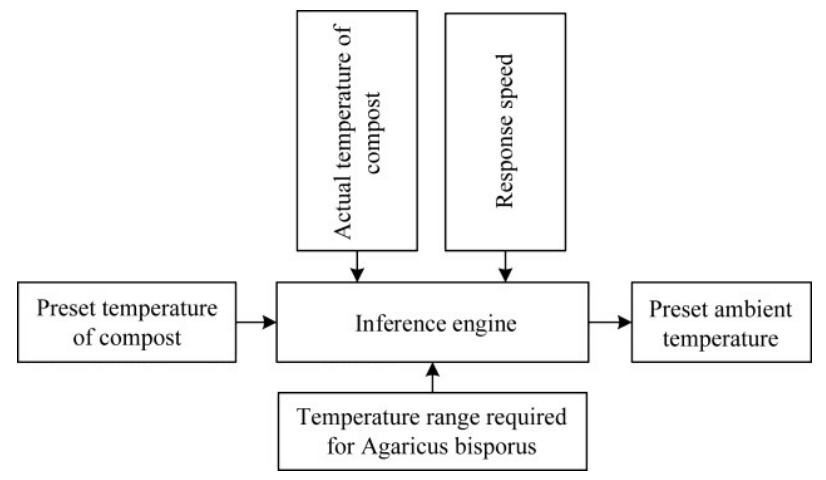

a. Reasoning of control value of compost temperature

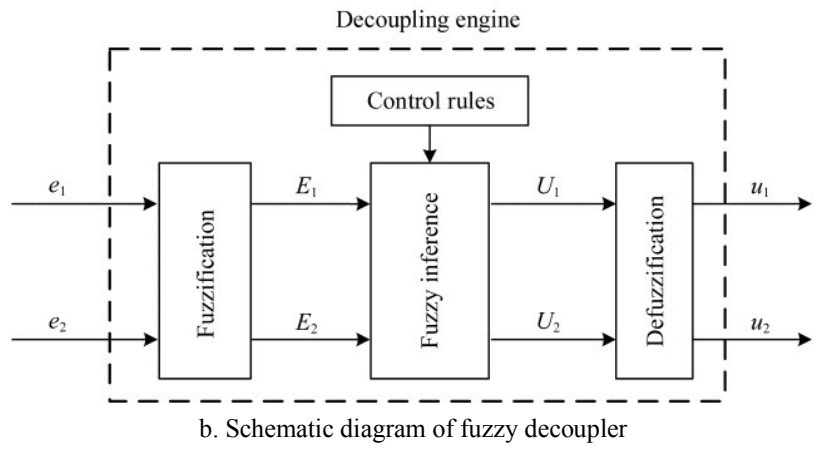

Figure 8 Inference and decoupling engine

In the process of $\mathrm{CO}_{2}$ concentration control, the sensor monitors the $\mathrm{CO}_{2}$ content in mushroom room in real-time and compares it with the preset value. The deviations of $\mathrm{CO}_{2}$ concentration and the change rate of deviation are used as the input of fuzzy controller. The control signal of ventilation execution equipment is obtained by fuzzy reasoning. Through the control of ventilation execution equipment, the actual $\mathrm{CO}_{2}$ concentration can reach the preset value. The interference of $\mathrm{CO}_{2}$ concentration control mainly comes from the external environment out of the mushroom house. The ventilation execution equipment needs to inhale the external air during the control process. The control speed will be affected by the $\mathrm{CO}_{2}$ concentration in external air. When the external air $\mathrm{CO}_{2}$ concentration is low, the control speed is fast, and the mushroom house $\mathrm{CO}_{2}$ concentration can reach the preset value in a short time. On contrary, when $\mathrm{CO}_{2}$ concentration in the external air is high, the control speed is slow, and the $\mathrm{CO}_{2}$ concentration in the mushroom room takes a long time to reach the preset value.

\subsection{Software workflow}

The main system software workflow is shown in Figure 9. After the system is powered on and initialized, the preset values of each environmental parameter should be set.

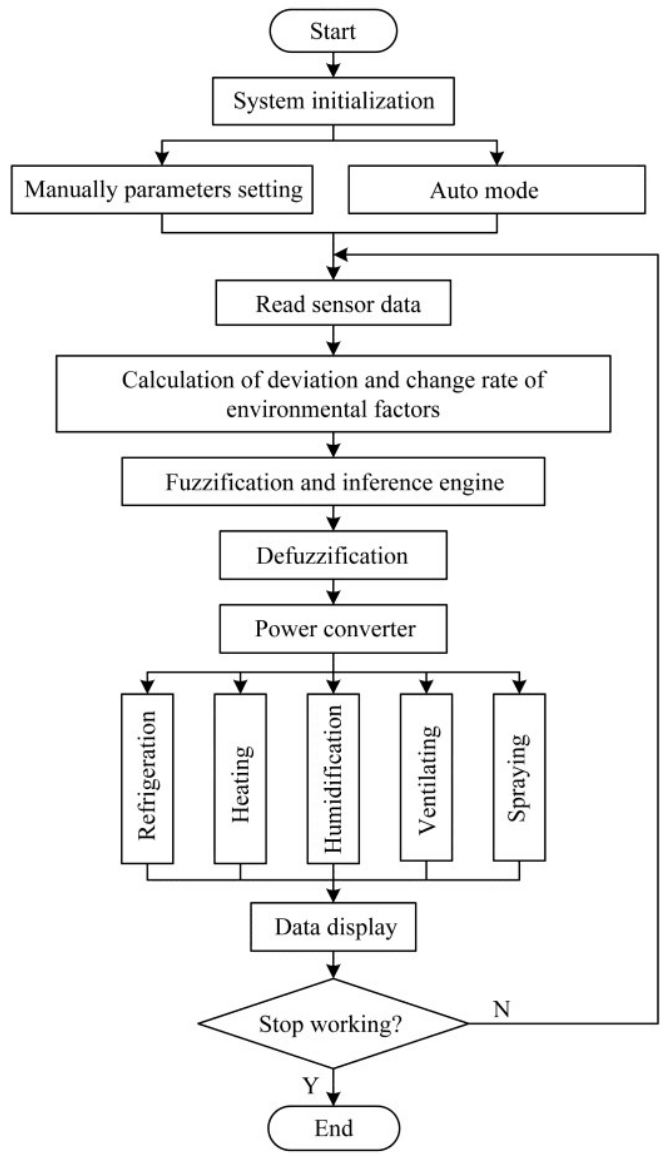

Figure 9 Flow chart of environment control system for industrialized production of Agaricus bisporus

There are two modes to set them. One is to set parameters manually, that is, the preset values of each environment are set according to the intention of the operator. The other is to set parameters automatically, that is, to set the preset values of each environment automatically according to the pre-stored settings in the system. After the parameters are set, the system begins to receive the data collected by various sensors, and calculates the deviations and change rate of them for each environment parameters. These values are used as inputs to enter the fuzzy control system for fuzzy processing and fuzzy reasoning to obtain the control output. The execution equipment works according to the control quantity. The human-computer interaction interface displays the real-time data and running parameters of each environmental factor. Finally, the actual values of each environmental factor reach and stabilize to preset value. 


\subsection{Interaction interface}

The interaction interface is mainly used for the display of real-time data and the setting of system parameters of the system, mainly including the main page, fault processing page, operation status page, and parameter setting page. Some interaction interface pages are shown in Figure 10.

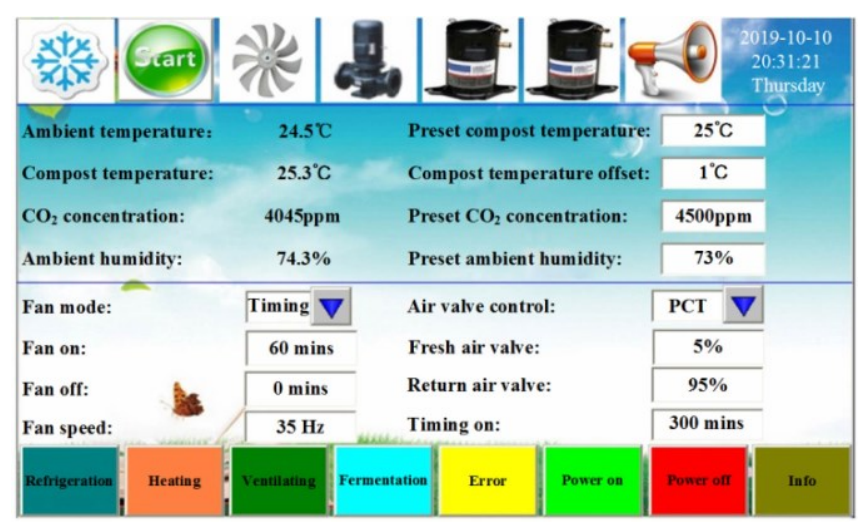

a. Main page

\begin{tabular}{|l|}
\hline \multicolumn{1}{|c|}{ Parameter setting } \\
\hline Item 1: Power parameters \\
\hline Item 2: Water pump parameters \\
\hline Item 3: Compressor parameters \\
\hline Item 4: Sensors parameters \\
\hline \hline Item 5: Protection parameter settings \\
\hline Item6: Temperature compensation parameter setting \\
\hline \hline Item 7: Auto mode parameters \\
\hline \hline Item 8: Manual control parameters \\
\hline
\end{tabular}

b. Setting page

Figure 10 Interaction interface

All inputs can be done with the touch screen. When users start to use it, they can check all environmental parameters in real-time. According to the actual environment condition of the mushroom house, the system can be started after the mode selection is set. The fault handling page is mainly used for overload protection and alarm. The information page can display the working conditions of execution equipment and monitor the operation effect of the execution equipment. The parameter setting page is mainly used to set various parameters of the control system, display the parameter items, and select and set the given items of the software.

\section{Experiment}

In order to verify the performance of the environment control device and system for the industrialized production of Agaricus bisporus, an experiment was conducted in the mushroom production laboratory in Henan University of Science and Technology, China from September to October 2019.

The control system was verified and tested during the actual growth process of Agaricus bisporus. The layout of the laboratory is shown in Figure 11. The laboratory is $6.5 \mathrm{~m}$ in length, $4 \mathrm{~m}$ in width and $4 \mathrm{~m}$ in height. A shelf made of metal was used to grow Agaricus bisporus. The mushroom shelf is $4.5 \mathrm{~m}$ long and $1.4 \mathrm{~m}$ wide. It has three layers, with a spacing of $0.5 \mathrm{~m}$ between each layer. The mushroom shelf was located in the central area of the mushroom house. The air supply outlet was located above one side, and the end was connected to a horizontally arranged air collecting bag with air outlets on it, so that the flowing cold/hot air can flow through each mushroom layer evenly.

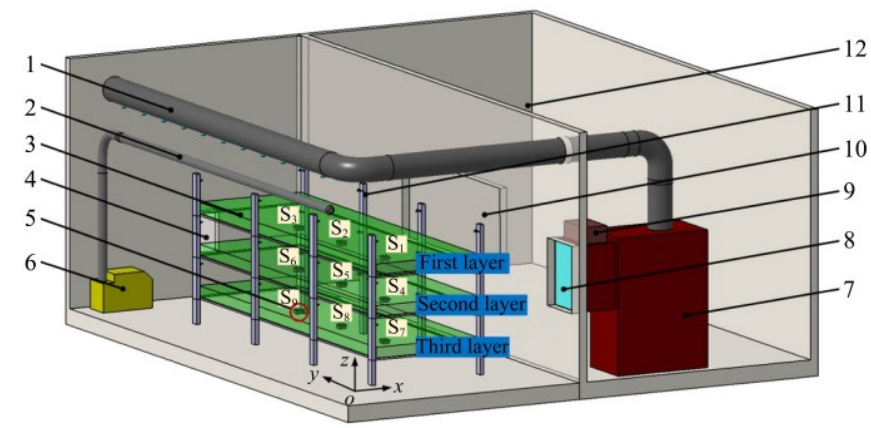

1. Air outlet pipe 2. Fog outlet pipe 3. Compost 4. Relief window 5. Sensor 6. Humidifier 7. Air conditioner 8. Return air window 9. Fresh air window 10. Observation window 11. Mushroom shelves 12. Walls

Figure 11 Layout of Agaricus bisporus production laboratory and experiment setup

For each environment factor, 9 sensors were used to monitor it. As shown in Figure 11, there were 3 installation positions in each layer, and they were points that cut the layer into four equal sections, i.e., points of quadrisection. Data from those 9 points were averaged and feedback to the system to control the temperature, humidity/ moisture and $\mathrm{CO}_{2}$. The sensors were connected with the PC via RS485 bus to transmit the data.

The control effect of environmental factors in mushroom house depends on the control precision, control efficiency, and control stability of the system. When the control factor enters the allowable error rang and continues to fluctuate within the range, it is considered that the system enters a stable state. The error ranges of culture soil temperature, environmental humidity, culture soil moisture and $\mathrm{CO}_{2}$ concentration were $\pm 0.5^{\circ} \mathrm{C}, \pm 1 \% \mathrm{RH}, \pm 10 \%$ and $200 \mu \mathrm{mol} / \mathrm{mol}$, respectively. The control error in the steady state of the system was used as an index of the control accuracy. The control efficiency is investigated with the system response speed which is defined as:

$$
\left\{\begin{array}{l}
v=\frac{e s}{t_{s}} \\
e s=\left|s_{s}-s_{c}\right|
\end{array}\right.
$$

where, $t_{s}$ is the minimum time for controlled environmental factor entering and staying within the error range (s), i.e., system adjustment time; es, $s_{s}$ and $s_{c}$ are the change of environmental factor, the difference of preset and error range, and initial values of environmental factor, respectively.

The control stability is investigated with uniformity of controlled environmental factors. The control uniformity of environmental factors is investigated by average value and standard deviation value of environmental factors at each point in mushroom shelf. The smaller the value is, the better the uniformity of environmental factor control.

\subsection{Temperature control}

\subsubsection{Temperature control accuracy}

The test was carried out in October 2019. Firstly, the preset temperature of compost was kept at $21{ }^{\circ} \mathrm{C}$. After the system was stable, the ambient temperature was $20.4^{\circ} \mathrm{C}$, and the temperature of compost was $21^{\circ} \mathrm{C}$. Then the preset temperature of compost was set to $18^{\circ} \mathrm{C}$. The control system was going to increase the cooling capacity to adjust the temperature. During the cooling process, the temperature value was recorded every 5 min until the environment and compost temperature were stable. The records of temperature are shown in Figure 12. 


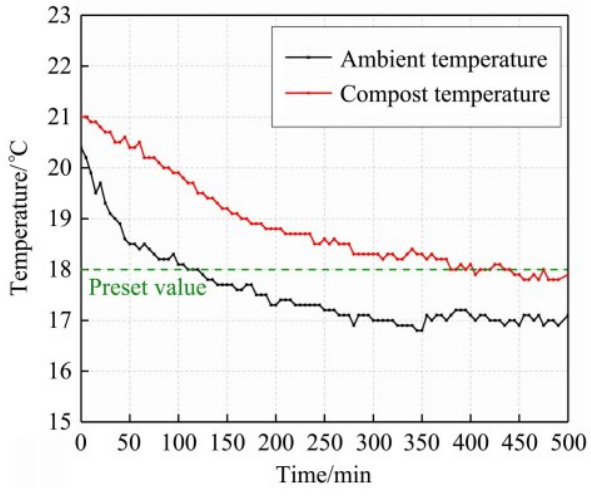

Figure 12 Environment and compost temperature control process

Figure 12 shows that the ambient temperature dropped faster than that of the compost. The temperature of the compost is indirectly controlled by the heat transfer from the ambient temperature. The temperature drop of the compost lags behind the ambient temperature, and the ambient temperature drops faster, which conforms to the control theory mentioned above. When the actual value was far from the preset value, the temperature regulating equipment operated with high power. The temperature decreased rapidly to improve the working efficiency; when the actual value was close to the preset value, the temperature regulating equipment operated with low power to avoid overshoot. Therefore, the decrease of ambient temperature was fast first and slow then, and the temperature change tended to be stable when it dropped to about $17^{\circ} \mathrm{C}$, which was the preset value of environment temperature, which was obtained by the system's independent decision-making by Equation (1). When the temperature difference was large, the temperature of the compost decreased a little faster; Finally, the compost temperature was stable in the allowable error range, and the response speed $v$ was about $0.56{ }^{\circ} \mathrm{C} / \mathrm{h}$.

Compared with the other systems for monitoring and controlling environmental temperature, this system has the advantage of higher accuracy for temperature control of compost. Especially in the fermentation stage, if the temperature control of the compost does not meet the requirements, it will lead to incomplete fermentation, slow or even stagnant hyphal growth, which will affect the emergence of mushrooms. In the growth stage, if the temperature of compost does not meet the requirements, it will affect the differentiation quality and quantity of fruiting body. The temperature of compost directly affects the mycelium development and fruiting body growth of Agaricus bisporus. The environment temperature mainly affects the space temperature of the fruiting body. It is difficult to meet the requirements for normal growth of Agaricus bisporus only by regulating the ambient temperature. Therefore, the control system for compost temperature proposed in this study can ensure the efficient production of Agaricus bisporus.

\subsubsection{Distribution of ambient temperature}

After the ambient temperature of the mushroom house is stable around the preset value, the air flow speed at different points in the mushroom house is different due to the different layout positions and sizes of the air supply outlet and air return outlet in the mushroom house. The air flow is fast near the air supply outlet and air return outlet, and slow if it is far away. It is necessary to test the distribution and change of the environment temperature of the mushroom house after the temperature is stable, as well as the accuracy and consistency of the data. The test also was carried out in October 2019. The preset temperature of the compost was kept at $21^{\circ} \mathrm{C}$. When the ambient temperature tended to be stable, the ambient and compost temperature was measured every $5 \mathrm{~min}$ for
$840 \mathrm{~min}$. The temperature parameters of the environment and compost are shown in Table 1.

Table 1 Statistics of temperature values in different positions of mushroom bed

\begin{tabular}{ccccc}
\hline \multirow{2}{*}{ Sensor location } & Minimum value & Maximum value & Mean value \\
\hline \multirow{4}{*}{ First layer } & $\mathrm{S}_{1}$ & 20.0 & 20.2 & 20.11 \\
& $\mathrm{~S}_{2}$ & 20.0 & 20.1 & 20.04 \\
& $\mathrm{~S}_{3}$ & 19.9 & 20.1 & 20.03 \\
\hline \multirow{5}{*}{ Second layer } & $\mathrm{S}_{4}$ & 20.3 & 20.5 & 20.40 \\
& $\mathrm{~S}_{5}$ & 20.0 & 20.3 & 20.22 \\
& $\mathrm{~S}_{6}$ & 19.9 & 20.2 & 20.06 \\
\hline \multirow{3}{*}{ Third layer } & $\mathrm{S}_{7}$ & 20.0 & 20.2 & 20.04 \\
& $\mathrm{~S}_{8}$ & 20.0 & 20.1 & 20.05 \\
& $\mathrm{~S}_{9}$ & 20.2 & 20.4 & 20.27 \\
\hline
\end{tabular}

Through the analysis Table 1 , it can be seen that the environment temperature values between monitoring points have little difference after the system-controlled temperature is stable. The difference between the maximum value and the minimum value of ambient temperature was less than $1^{\circ} \mathrm{C}$; the difference of ambient temperature averages between points was less than $0.5^{\circ} \mathrm{C}$. The temperature difference between layers was not obvious. The uniformity of the temperature distribution in the mushroom room was good, which indicates that the arrangement of the return air and air supply device was reasonable, the air fluidity and circulation were good.

\subsubsection{Distribution of compost temperature}

To verify the uniformity of compost temperature distribution, a temperature probe was used manually to measure temperature and moisture in different positions of the compost. The portable soil thermometer is Delta Trak 11063 Probe Thermometer (Delta Trak Inc., Pleasanton, USA). The temperature measurement range is $-40^{\circ} \mathrm{C}-155^{\circ} \mathrm{C}$, the accuracy is $\pm 0.5^{\circ} \mathrm{C}$, the resolution is $0.1{ }^{\circ} \mathrm{C}$, and the waterproof level is IP56.

During the normal growth of Agaricus bisporus, the preset temperature of compost was kept at $21^{\circ} \mathrm{C}$. When the temperature of the compost measured by the system was stabilized, 24 points on each layer were measured. The temperature distribution map is shown in Figure 13.
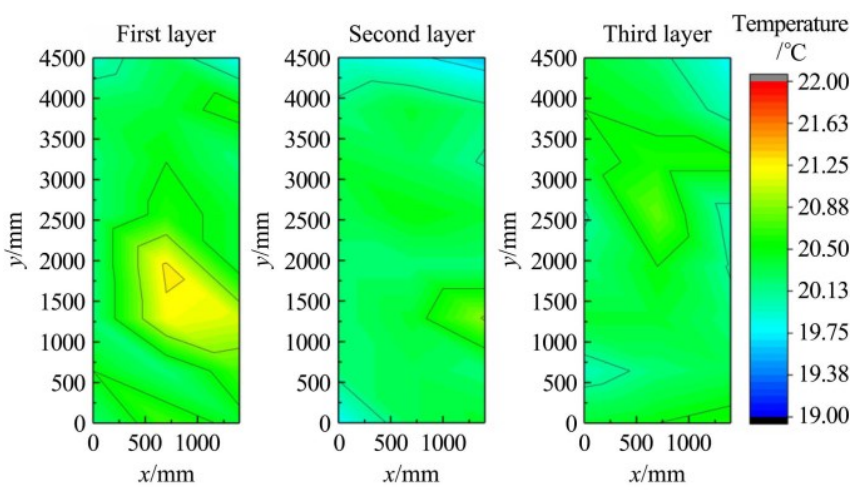

Figure 13 Temperature distribution of compost at different positions in mushroom bed

Figure 13 shows that the compost temperatures of different points are also similar after the ambient temperature is stable at about $20^{\circ} \mathrm{C}$, where the maximum temperature value is $21.3^{\circ} \mathrm{C}$, the minimum temperature value is $19.6^{\circ} \mathrm{C}$, and the maximum temperature difference between different points is less than $1^{\circ} \mathrm{C}$. The compost temperature fluctuated within $0.5^{\circ} \mathrm{C}$ which meets the design requirements. In general, the temperature distributions of 
the second- and third- layer mushroom were more uniform. The temperature of the middle region of the first layer was higher than the other regions. The main reason was that the first layer was far away from the air outlet, and the compost in this region was in little depression, and the flow of the cold air was influenced to a certain extent. The lowest temperature of compost appeared on the short side of the second layer due to the high wind speed in that area. The average temperature of the first layer was the highest $\left(20.4^{\circ} \mathrm{C}\right)$ and the second layer was the lowest $\left(20.2^{\circ} \mathrm{C}\right)$. The difference between average temperatures of layers was small and the distribution between layers was uniform. The analysis shows that the temperature distribution of the compost in the mushroom house environment is uniform, and the system control effect is good.

\subsection{Environment humidity control}

This experiment was to verify the accuracy and efficiency of the environmental humidity control system. The test began in the transition phase of the growth of the mycelium to the fruiting body. The initial humidity of the environment was $74.8 \% \mathrm{RH}$ and the target humidity of the environment was $85 \% \mathrm{RH}$. The humidity value was recorded every $5 \mathrm{~min}$ for $400 \mathrm{~min}$. The data records are shown in Figure 14.

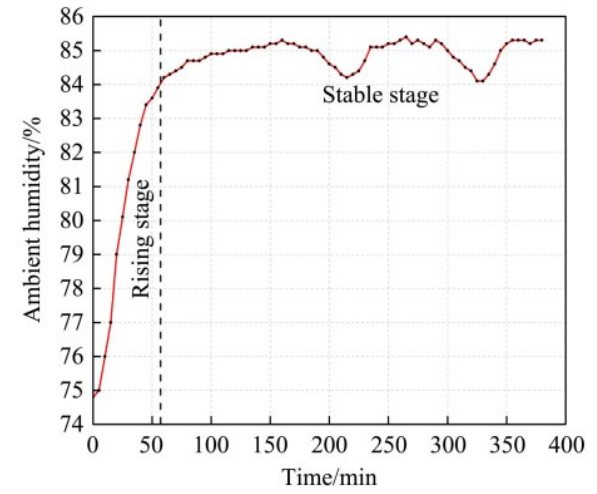

Figure 14 Test results of environment humidity control

Figure 14 shows that the response speed of environmental humidity is fast. The response speed $v$ was about $9.86 \% / \mathrm{h}$. It took about 56 min rising to the stable stage of the system and kept within the error range. After the humidity value was stable, the highest and lowest environmental humidity was $85.2 \% \mathrm{RH}$ and $84.1 \% \mathrm{RH}$, respectively. The upper and lower range of the regulated humidity difference was less than $2 \% \mathrm{RH}$. The control process of ambient humidity was fast and the control effect was good. There were two humidity troughs in the stable stage of environmental humidity, where the humidity values were $84.2 \% \mathrm{RH}$ and $84.1 \% \mathrm{RH}$, respectively. The reason was that the humidifier was gone to stop working after reaching the preset value. The air continued to circulate and the environmental humidity drops. The humidifier was gone to continue to work when it drops to the trigger value. The difference in environment humidity control was less than $2 \%$ $\mathrm{RH}$, which meets the requirements for the growth of Agaricus bisporus.

The traditional method is to increase the environmental humidity by sprinkling water on the floor and walls of mushroom houses. This method can effectively improve the humidity of mushroom room. However, the utilization rate of water is low and the loss of water quantity is large. And soaking the wall and the ground for such a long time will shorten the service life of mushroom house. Too much water on the ground is also easy to breed miscellaneous bacteria, increase the cost of treatment of miscellaneous bacteria, and affect the yield of Agaricus bisporus.
The system adopts the atomizing humidifier to increase the moisture of the mushroom house. The humidification effect is good; the use of water is reduced; the energy use and control are efficient.

\subsection{Compost moisture control}

To verify the uniformity of compost moisture distribution, Jk-100f soil moisture probe (Youke Instruments Co., Ltd., Xinghua, China) was used to measure the moisture of the compost in different positions. It uses a high cycle scanning method to measure soil moisture, with a measurement range of $0-100 \%$, resolution of $0.1 \%$, and accuracy of $\pm 0.5 \%$.

The growth and development of Agaricus bisporus have a high requirement on the moisture of the compost ${ }^{[29]}$. In order to test the effect of compost moisture control system, the test was carried out after the compost was covered with soil on October 9th, 2019. When the difference between the preset value and the actual value of the compost moisture was large, the spray system was turned on. After absorbing water, the measured value of moisture rose gradually because of the slow water infiltration rate of compost. The equipment continued to spay until the measured moisture was close to the preset value after the compost fully absorbed water, and the sprinkler equipment stopped working. Similar to the test of compost temperature control, the moisture of compost was recorded at different points on the mushroom shelf. 24 points were measured evenly in each layer, and the results are shown in Figure 15.
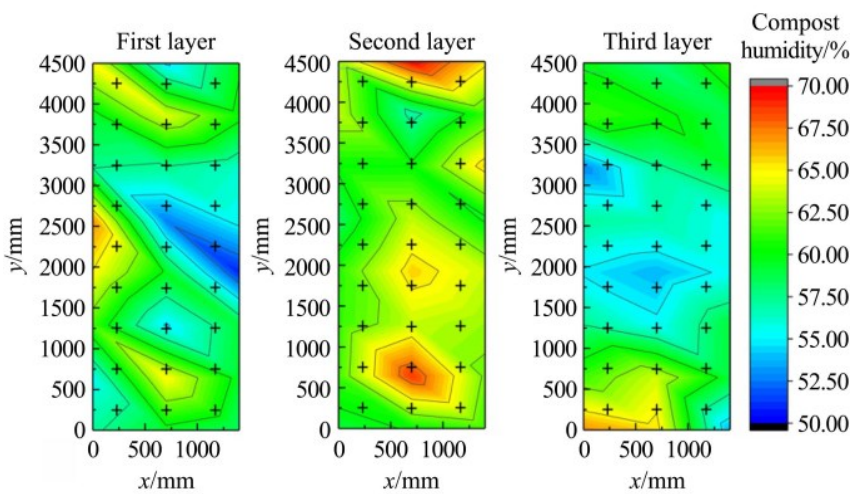

Figure 15 Test results of control of compost moisture

Figure 15 shows that the uniformity of moisture distribution of compost is poor. The highest and lowest moistures were $69.9 \%$ and $50.9 \%$, respectively. The difference between them was $19 \%$. The minimum moisture had exceeded the moisture range required by the compost. The spraying uniformity of spray equipment was poor. All the test points were in the optimum moisture of compost, and the standard deviation after spraying was about 4.04. The compost moisture meets the growing demand of Agaricus bisporus. Because the spray quantity of sprinkler was difficult to control accurately, the moisture uniformity was poor. The coverage area of each sprinkler was uncertain and might be intersected, which leads to high moisture content in some areas. Leakage spraying occurred in the low moisture area. Overall, the uniformity of moisture distribution was poor, and the spray equipment needed to be improved. In the future, studies should focus on the technologies for precision control of water pressure in the sprinkler pipeline, as well as the design and development of variable sprinkler.

\section{$5.4 \mathrm{CO}_{2}$ concentration control}

During the growth of Agaricus bisporus, oxygen is constantly consumed and $\mathrm{CO}_{2}$ is discharged. Therefore, the main task of the control system is to control and reduce $\mathrm{CO}_{2}$ concentration. Test of $\mathrm{CO}_{2}$ concentration control was conducted on October 19th, 2019 at transition stage from mycelium growth to fruiting body growth. At 
the beginning of the test, the $\mathrm{CO}_{2}$ concentration value was $3120 \mu \mathrm{mol} / \mathrm{mol}$, and the control target was set to $1000 \mu \mathrm{mol} / \mathrm{mol}$. The $\mathrm{CO}_{2}$ was continuously measured for 265 min using 9 sensors, and the data were read every $5 \mathrm{~min}$. The test results are shown in Figure 16.

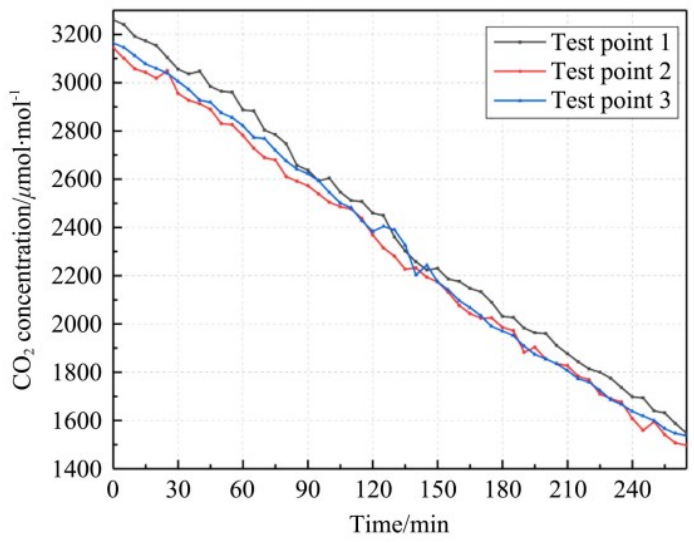

a. First layer

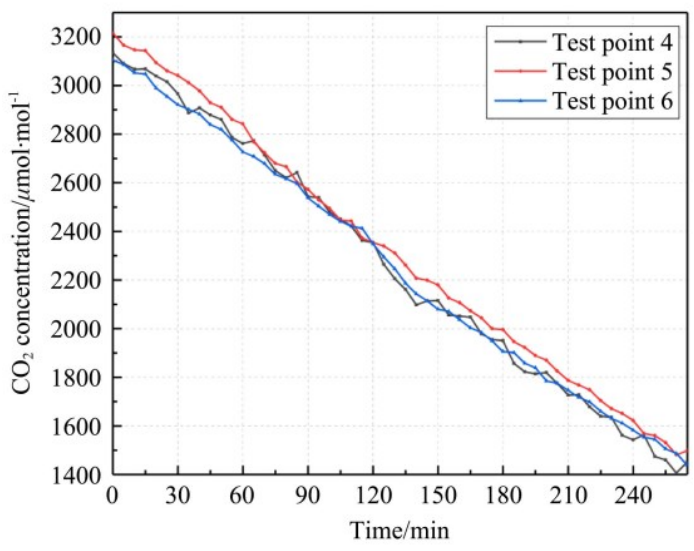

b. Second layer

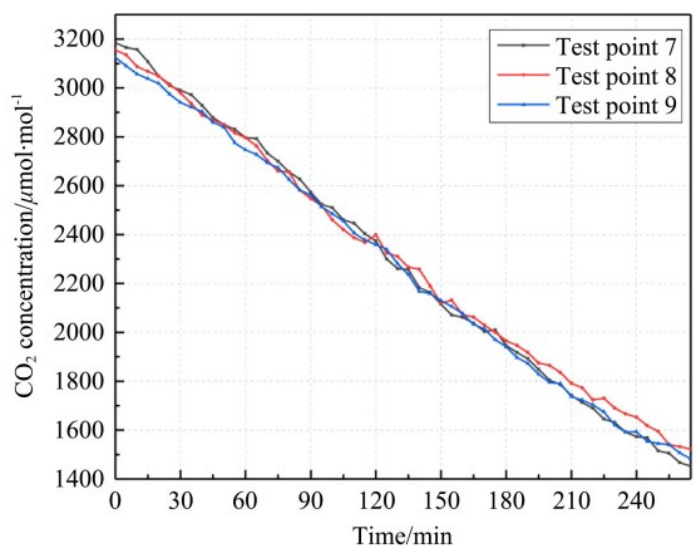

c. Third layer

Figure 16 Test results of $\mathrm{CO}_{2}$ concentration control

Figure 16 shows that the $\mathrm{CO}_{2}$ concentration decreases to about $1500 \mu \mathrm{mol} / \mathrm{mol}$ within $265 \mathrm{~min}$ during the monitoring period. $\mathrm{CO}_{2}$ concentration was reduced rapidly in the regulation period, and the control efficiency of the ventilation execution equipment was high. The decreasing trend of $\mathrm{CO}_{2}$ concentration at each monitoring point was close, which indicates that the air flow in mushroom room was fast and the control stability of the system was good. The ventilation execution equipment worked well in the process of operation. The air cycle was rapid and comprehensive, and the distribution of $\mathrm{CO}_{2}$ concentration was uniform. The difference in $\mathrm{CO}_{2}$ concentration at each monitoring point was small. At the same time, the difference between the maximum and the minimum was less than $200 \mu \mathrm{mol} / \mathrm{mol}$.

\section{Conclusions}

(1) In this study, a set of environment control systems for industrialized production of Agaricus bisporus was developed, four sets of control equipment were developed, and three fuzzy controllers were designed to realize the monitoring and control of five environmental factors. The system can accurately monitor and control the environmental factors in mushroom house.

(2) The main controller used three fuzzy control strategies to control the environment factors of the mushroom house to eliminate the coupling effect between factors. The control effect fully meets the environment required for the growth of Agaricus bisporus.

(3) The test results showed that the temperature difference between different points of the compost was less than $1{ }^{\circ} \mathrm{C}$, the control accuracy of compost temperature was less than $\pm 0.5^{\circ} \mathrm{C}$, response speed was $0.5^{\circ} \mathrm{C} / \mathrm{h}$. The response speed of environmental humidity was $9.86 \% / \mathrm{h}$, humidity control error was less than $\pm 2 \%$ $\mathrm{RH}$; The moistures of different sites of compost were in the range of $50 \%-70 \%$, the standard deviation of water content after spray was about 4.04; The control accuracy of $\mathrm{CO}_{2}$ concentration was less than $\pm 200 \mu \mathrm{mol} / \mathrm{mol}$. The overall performance of the designed environmental control system was stable and reliable, which could meet the requirements of environment factors for the growth of Agaricus bisporus.

\section{Acknowledgements}

The authors acknowledge Mr. Jiangtao Zhang from Luoyang Aojite Biotechnology Co., Ltd. for his technical support for the cultivation of Agaricus bisporus during the experiment. This study was supported by the National Key R\&D Plan Key projects of Scientific and technological Innovation Cooperation between Governments (Grant No. 2019YFE0125100), and the Basic Research Project of the Key Scientific Research Project Plan of Henan University (Grant No. 19zx015).

\section{[References]}

[1] Xue Y, Xie J, Xu X S, Yong L, Hu B, Liang J, et al. UPLC-QqQ/MS combined with similarity assessment of 17 nucleic acid constituents in 147 edible fungi from Sichuan Basin, China. Food Research International, 2019; 120: 577-585.

[2] Geng Y C, Zhang T, Liu H B, Zhai L M, Yang B, Wang H Y. Effects of different briquetting modes on production of Agaricus bisporus. Transactions of the CSAE, 2016; 32(S2): 275-278. (in Chinese)

[3] Reis F S, Barros L, Martins A, Ferreira I C F R. Chemical composition and nutritional value of the most widely appreciated cultivated mushrooms: An inter-species comparative study. Food \& Chemical Toxicology, 2012; 50(2): 191-197.

[4] Colmenares-Cruz S, Sanchez J E, Valle-Mora J. Agaricus bisporus production on substrates pasteurized by self-heating. Amb Express, 2017; 7(1): 1-9.

[5] Kimatu B M, Zhao L Y, Biao Y, Ma G X, Yang W J, Pei F, et al. Antioxidant potential of edible mushroom (Agaricus bisporus) protein hydrolysates and their ultrafiltration fractions. Food Chemistry, 2017; 230(SEP.1): 58-67.

[6] Dai F, Yang J, Zhao W Y, Li Z G, Xin S L, Zhang F W. Design and experiment of key assorted device based on factory production of Agaricus bisporus. Transactions of the CSAE, 2018; 34(6): 43-51. (in Chinese)

[7] Shamshiri R R, Kalantari F, Ting K C, Thorp K R, Hameed I A, Weltzien $\mathrm{C}$, et al. Advances in greenhouse automation and controlled environment agriculture: A transition to plant factories and urban agriculture. Int $\mathrm{J}$ Agric \& Biol Eng, 2018; 11(1): 1-22.

[8] Mohd S A M, Salinda B, Musa M M, Mohamad S Z A. Internet of things based smart environmental monitoring for mushroom cultivation. 
Indonesian Journal of Electrical Engineering and Computer Science, 2018; 10(3): $847-852$

[9] Takakura T. Research exploring greenhouse environment control over the last 50 years. Int J Agric \& Biol Eng, 2019; 12(5): 1-7.

[10] Mao H P, Jin C, Chen Y. Research progress and prospect on control methods of greenhouse environment. Transactions of the CSAM, 2018; 49(2): 1-13. (in Chinese)

[11] Du S F, Li Y X, Ma C W, Chen Q Y, Yang W Z. Current situation on greenhouse environment control system modes in China. Transactions of the CSAE, 2004; 20(1): 7-12. (in Chinese)

[12] Mohammed M F, Azmi A, Zakaria Z, Tajuddin M F N, Isa Z M, Azmi S A. IoT based monitoring and environment control system for indoor cultivation of oyster mushroom. Journal of Physics: Conference Series, 2018; 1019: 1-8.

[13] Dai J F, Luo W H, Qiao X J, Wang C. Model-based decision support system for greenhouse heating temperature set point optimization. Transactions of the CSAE, 2014; 45(4): 236-243. (in Chinese)

[14] Li T, Ji Y H, Zhang M, Sha S, Jiang Y Q. Tomato photosynthetic rate prediction models under interaction of $\mathrm{CO}_{2}$ enrichments and soil moistures. Transactions of the CSAM, 2015; 46(S1): 208-214. (in Chinese)

[15] Walker J N. Predicting temperatures in ventilated greenhouses. Transactions of the ASAE, 1965; 8(3): 445-448.

[16] Wang S J, Deltour J. Simulation of the application of different control methods to the greenhouse heating system. Journal of Zhejiang Agricultural University, 1992; 18: 738-743.

[17] Uaink T C A J, Bot G P J, Dixhoorn J J. Computer control of greenhouse climates. Acta Horticulturae, 1978; 87: 265-272.

[18] Jones J W, Dayan E, Allen L H. A dynamic tomato growth and yield model (TOMGRO). Transactions of the ASAE, 1991; 34(2): 663-672.

[19] Van H E J. Greenhouse climate management: an optimal control approach. $\mathrm{PhD}$ dissertation. Wageningen: Wageningen Agricultural University, 1994; 329p.

[20] Takayama K, Nishina H, Mizutani K. Chlorophyll fluorescence imaging for health condition monitoring of tomato plants in greenhouse. Acta Hort, 2011; 893: 333-339.

[21] Chen L J, Du S F, He Y F, Liang M H. Design and simulation of greenhouse temperature hierarchical control system. Transactions of Beijing Institute of Technology, 2018; 38(8): 835-840. (in Chinese)

[22] Li Y X, Du S F. Advances of intelligent control algorithm of greenhouse environment in China. Transactions of the CSAE, 2004; 20(2): 267-272. (in Chinese)

[23] Feng L F. Research on modern edible fungi growth control system based on internet of things technology. Master dissertation. Zhengzhou: North China University of Water Resources and Electric Power, 2018; 56p. (in Chinese)

[24] Han Q H, Li S J, Zhang Y C, Mao Z H, Wu H, Bai L F. Remote monitoring system of edible fungus industrial cultivation environment. Transactions of the CSAM, 2007; 38(2): 115-119. (in Chinese)

[25] Kwon J K, Kim S H, Jeon J G, Kang Y K, Jang K Y. Development of environmental control system for high-quality shiitake mushroom (Lentinus edodes (Berk.) Sing.) Production. Journal of Biosystems Engineering, 2018; 43(4): 342-351.

[26] Song C. Design and realization of the monitoring system of edible fung factory production. Master dissertation. Taian: Shandong Agricultural University, 2015; 66p. (in Chinese)

[27] Ardabili S F, Mahmoudi A, Gundoshmian T M, Roshanianfard A. Modeling and comparison of fuzzy and on/off controller in a mushroom growing hall. Measurement, 2016; 90: 127-134.

[28] Zheng Z Q, Luo X. Effect of temperature and humidity control on ecological high yield cultivation effect of edible fungi. Edible Fungi of China, 2019; 38(8): 21-24. (in Chinese)

[29] Bian Y B. Edible mushroom cultivation. Beijing: Higher Education Press, 2017; 338p. ISBN: 9787040466508.

[30] Arjuna M, Soh Y Y. Environmental monitoring and controlling system for mushrooom farm with online interface. International Journal of Computer Science \& Information Technology, 2017; 9(4): 17-28.

[31] Zadeh L A. Toward a generalized theory of uncertainty (GTU) - an outline. Information Sciences, 2005; 172(1): 1-40.

[32] Jin X, Cheng K K, Ji J T, Zhao K X, Du X W, Ma H. Intelligent vibration detection and control system of agricultural machinery engine. Measurement, 2019; 145: 503-510.

[33] Jin X, Yuan Y W, Ji J T, Zhao K X, Li M Y, Chen K K. Design and implementation of anti-leakage planting system for transplanting machine based on fuzzy information. Computers and Electronics in Agriculture, 2020; 169: 105204. doi: 10.1016/j.compag.2019.105204.

[34] Salgado P, Cunha J B. Greenhouse climate hierarchical fuzzy modelling. Control Engineering Practice, 2005; 13(5): 613-628.

[35] Castañeda-Miranda R, Ventura-Ramos E, Peniche-Vera R D R, Herrera-Ruiz G. Fuzzy greenhouse climate control system based on a field Programmable Gate Array. Biosystems Engineering, 2006; 94(2): 165-177.

[36] Ai H B, Wei J H, Qiu Q, Zheng W G. Design of intelligent control system for micro plant factory. Transactions of the CSAM, 2013; 44(S2): 198-204. (in Chinese) 